\title{
Currículo, identidade e relações étnico-raciais: a escola mediando as fronteiras da in/exclusão
}

\section{Curriculum, identity and ethnic-racial relations: the school mediating the borders of in/exclusion}

\section{Currículum, identidad y relaciones étnico-raciales: la escuela que media las fronteras de la in/exclusión}

\author{
Cristiane Bartz de Ávila ${ }^{1}$ \\ Álvaro Moreira Hypolito ${ }^{1}$
}

DOI: http://dx.doi.org/10.20435/serie-estudos.v25i54.1386

\begin{abstract}
Resumo: O presente trabalho tem como foco analisar fatores que podem influenciar o currículo escolar para uma educação crítica, no sentido de mediar as fronteiras da in/exclusão em relação às questões étnico-raciais. Delineia um breve histórico sobre as relações desiguais que permearam o período colonial e pós-colonial no Brasil, com evidência para a luta dos africanos e afro-brasileiros, no sentido de busca de uma condição de escolarização, a fim de uma inserção social. São chamados alguns autores que contribuíram na sociologia da educação para os debates em torno da categoria currículo. A intenção foi partir de breves descrições de seus pensamentos, destacar as teorias críticas e pós-críticas e sua relação com respeito ao papel da escola na sociedade. A partir daí, o artigo debate o porquê de algumas legislações serem cumpridas ou não. Quais interesses e relações de poder permeiam o currículo escolar? Por que uma lei inclusiva como a 11.645/2008 não consegue estar presente de forma efetiva no currículo escolar? Questões sobre performatividade e gerencialismo nos ajudam a pensar sobre a problemática levantada. Por fim, o texto encaminha como alternativa a ideia de microrresistências ao poder instituído, em que uma pedagogia culturalmente relevante pode ser uma das formas para que a escola medeie as fronteiras entre a in/exclusão.
\end{abstract}

Palavras-chave: currículo; identidade; relações étnico-raciais.

Abstract: The present work focuses on analyzing factors that can influence the school curriculum for a critical education, in order to mediate the frontiers of in/exclusion concerning ethnicracial issues. It outlines a brief history of the unequal relations that permeated the colonial and postcolonial period in Brazil, with evidence for the struggle of Africans and Afro-Brazilians toward a better condition of schooling to a social inclusion. Some authors of the sociology of education are called to contribute to the debates around the curriculum. The intention was to start from brief descriptions of their thoughts, to highlight critical and post-critical theories and their relationship

\footnotetext{
${ }^{1}$ Universidade Federal de Pelotas (UFPel). Pelotas, Rio Grande do Sul, Brasil.
} 
for the role of school in society. From there, the article discusses the reason some legislations are fulfilled or not. What interests and power relations permeate the curriculum? Why cannot an inclusive law such as $11.645 / 2008$ be effectively present in the curriculum? Questions about performativity and managerialism help us to think about the problem raised. Finally, the text proposes as an alternative the idea of micro-resistances to established power, in which a culturally relevant pedagogy can be one of the ways for the school to measure the boundaries between inclusion/exclusion.

Keywords: curriculum; identity; ethnic-racial relations.

Resumen: El presente trabajo tiene como foco de análisis factores que poden influenciar el currículum escolar para una educación crítica, en el sentido de mediar las fronteras de la in/ exclusión con relación a las cuestiones étnico-raciales. Delinea un breve resumen histórico sobre las relaciones que se presentaban en el período colonial y el poscolonial en Brasil, con evidencia para la lucha de los africanos y los afrobrasileños en la búsqueda de una mejor condición de escolarización para la inserción social. Algunos autores de la sociología de la educación son llamados para el debate en torno del currículum. La intención fue, a partir de breves descripciones de sus pensamientos, destacar las teorías críticas y proscriticas con relación al papel de la escuela y de la sociedad. A partir de este punto, el artículo debate por qué se cumplen o no algunas leyes legislativas. ¿Cuáles son los intereses y las relaciones de poder que permean el currículum escolar? ¿Por qué una ley inclusiva como la 11.645/2008 no está presente de forma efectiva en el currículum escolar? Cuestiones sobre performatividad y gerencialismo pueden ser relevantes para esta problemática. Por fin, o texto indica como alternativa la idea de micro resistencias al poder institucionalizado, de modo que una pedagogía cultural relevante puede ser una de las alternativas para que la escuela haga la mediación de las fronteras entre la inclusión y la exclusión.

Palabras clave: currículum; identidad; relaciones étnico-raciales.

\section{PALAVRAS INICIAIS}

Ao iniciarmos este debate, parece-nos importante que possamos traçar um panorama a respeito de como a etnia africana e afro-brasileira esteve alijada dos planos sociais, econômicos e culturais durante o processo de colonização brasileira. Neste ínterim, falar em escolarização para esses grupos étnicos parecia algo fora daquele contexto.

O colonialismo no continente americano, sustentado pela escravização africana, trouxe uma mancha histórica que perdura até nossos dias. Foram praticamente cerca de trezentos anos de trabalho escravizado, no qual o negro foi submetido às mais diversas atrocidades, fisicamente, moralmente e culturalmente.

Ao negro, o destino reservado era a perda de suas tradições, pois, desde o momento em que era negociado, ainda no continente africano, havia um ritual 
para o embarque. O objetivo era prepará-lo para a nova vida além-mar. O africano deveria dar voltas em torno do baobá (ver ÁVILA, 2014, p. 63-4), árvore sagrada para os africanos, com a finalidade de que ele esquecesse a antiga vida e partisse livre de suas memórias para a América. Sobre esquecimentos e silêncios a respeito de uma cultura, Joel Candau (2004) diz serem “[...] la negación de la memoria. De lo que podemos hablar en este caso es de asesinato de la memoria: antes de manipularla, la parte de verdad que hay en toda memoria es negada a priori" (CANDAU, 2004, p. 76).

Dessa maneira, as fronteiras entre a memória e o esquecimento são tênues; no caso citado acima, todo o simbolismo em torno da árvore africana fazia com que se ritualizasse o processo de esquecimento da cultura africana, que, apesar de sofrer todo o tipo de repressão, acabou se recriando além-mar a partir de variados processos de resistência elaborados pelos africanos.

Chegando aqui, eram afastados de suas famílias e forçados ao trabalho pesado ao som de chibatadas, entretanto não podemos deixar de ter em mente que os conhecimentos adquiridos pelo ser humano nunca são perdidos ou esquecidos, estes são reorganizados a partir das situações concretas pelas quais eles vivenciam. Dessa forma, o africano teve de se adaptar à nova condição, lutando, resistindo e negociando. Essa luta poderia ser silenciosa ou violenta. A partir de relações de compadrio, pegando em armas ou refugiando-se nos quilombos².

Thomas Skidmore (1976) faz uma comparação entre a escravização nos Estados Unidos e no Brasil. O autor demonstra, por meio de diversos estudiosos do tema, que no Brasil houve uniões de portugueses com indígenas e africanos. Dessas uniões, resultaram miscigenações que colaboraram para a defesa do "mito da democracia racial" que perdurou por longo período da história brasileira. De modo contrário, nos Estados Unidos, houve uma segregação rígida; dessa forma, foi atribuído a esses fatores o maior desenvolvimento do primeiro país em detrimento do segundo país.

\footnotetext{
2 Segundo Alfredo Wagner Berno de Almeida, em 1740 o Conselho Ultramarino definia o termo Quilombo como "toda habitação de negros fugidos, que passem de cinco, em parte despovoada, ainda que não tenham ranchos levantados e nem se achem pilões nele" (ALMEIDA, 1999, p. 47). Entretanto o mesmo autor discorre sobre a evolução do termo quilombo no sentido de demonstrar que este conceito foi generalizado durante a escravização. Segundo o autor, neste período existiram outras formas de convivência entre grupos de escravizados e senhores de terras, inclusive com relações de dependência contrárias ao que preconizava o senso comum.
} 
Thomas E. Skidmore (1976) trabalha com a ideia de que no Brasil vários fatores culminaram com a abolição, entre eles, a pressão estrangeira, as correntes filosóficas e os estudos da época, tais como o pensamento positivista, o materialismo e o evolucionismo. Segundo o autor, esses fatores foram cruciais, pois penetraram nas ideias dos jovens da elite da época, bem como na Escola Militar. $\mathrm{O}$ autor destaca que, próximo à abolição, nem o exército nem os juízes davam atenção às reclamações dos donos dos escravos fujões. Possivelmente, esse fato se deu porque os escravos lutavam seguidas vezes no exército e seria uma incoerência em tempos de paz voltar a caçá-los, tratando-os como inimigos.

Seguindo esse raciocínio, Florestan Fernandes (2008) aponta para a ideia de que a abolição foi reivindicada por muitos, mas não foi planejada para inserir o negro na sociedade e na economia brasileira. Dessa maneira, muitos ex-escravizados e libertos ficaram à margem da sociedade, conseguindo alguns poucos inserir-se no mercado por conta de apadrinhamentos e de esquecimento ou silêncio no que se refere às suas raízes.

No que tange à educação, as primeiras formas de escolarização no Brasil surgiram a partir da iniciativa dos padres jesuítas, que tinham como intenção cuidar da educação dos filhos da elite, bem como catequizar os indígenas. ${ }^{3}$

A educação formal foi negada aos "subalternos", principalmente aos indígenas e aos africanos. Esses continuaram recebendo ensinamentos, em sua maioria, a partir da tradição oral, como já acontecia em terras americanas e em grande parte do continente africano. Nesse contexto, a figura feminina africana toma destaque como aglutinadora de tradições ${ }^{4}$.

\footnotetext{
${ }^{3}$ Os indígenas sofreram com o primeiro contato com os europeus e continuaram sofrendo contínuo processo de extermínio. Sobre esse assunto, seria preciso outro trabalho à parte. Em relação à educação, embora tenha ocorrido o processo de catequese nas chamadas Missões Jesuíticas, podemos dizer que seu objetivo era tornar o indígena mais dócil para aceitar sua nova condição subalternizada.

${ }^{4}$ Se não fosse pela interferência dessas mulheres, provavelmente as tradições, tais como a própria língua, espiritualidade e culinária, seriam perdidas devido às várias proibições às quais os africanos e afro-brasileiros foram submetidos. Segundo Ávila e Ribeiro (2013), as “Tias Minas”, em Pelotas, RS, por exemplo, foram mulheres negras, escravizadas ou libertas que vendiam seus quitutes no Mercado Público, na porta da Igreja e em lugares públicos. A partir dos conhecimentos sobre a religiosidade africana e culinária tanto africana quanto portuguesa, fizeram parte de um processo de hibridização cultural, sendo as responsáveis por manter parte das tradições culturais africanas ao mesmo tempo em que enfrentavam tantas adversidades e a sobreposição da cultura portuguesa.
} 
Apesar da abolição em 1888, segundo Olívia Cunha e Flávio Gomes (2007), o projeto de nação não incluiu o negro como cidadão; incentivando a migração, o governo diminuiu ainda mais a oportunidade dos negros de galgarem postos de trabalho condizentes com a condição cidadã.

Quanto ao acesso à educação formal, segundo Mariléia dos Santos Cruz:

A necessidade de ser liberto ou de usufruir a cidadania quando livre, tanto durante os períodos do Império, quanto nos primeiros anos da República, aproximou as camadas negras da apropriação do saber escolar, nos moldes das exigências oficiais. Sendo assim, embora não de forma massiva, camadas populacionais negras atingiram níveis de instrução quando criavam suas próprias escolas; recebiam instrução de pessoas escolarizadas; ou adentravam a rede pública, os asilos de órfãos e escolas particulares. (CRUZ, 2005, p. 27-8).

A autora vai discorrendo sobre algumas experiências, em que, mesmo o negro sendo alijado das políticas públicas governamentais oficiais, esforçava-se para apropriar-se dos saberes formais exigidos socialmente; cita em seu trabalho, também, algumas iniciativas, revelando que as informações ainda são escassas, e menciona uma experiência educacional que chama atenção por ser no Quilombo da Fazenda Lagoa-Amarela, em Chapadinha, no Estado do Maranhão, criada pelo negro Cosme. A autora ainda cita outros trabalhos que trazem experiências da educação de negros ${ }^{5}$, entretanto as condições de permanência nas instituições escolares acabavam sendo um entrave a esse grupo étnico, o qual tinha em sua percepção que a escolarização seria um caminho para a ascensão socioeconômica. Conforme podemos depreender das palavras das autoras Ana Laura Mendes e Bruna Pereira Alves (2011), estas também compartilham dessas ideias:

Os negros perceberam que para tentar alcançar a igualdade, para não serem mais considerados como a raça inferior, deveriam se unir para lutar por seus direitos, por meio de reivindicações, em busca de conseguir o respeito, dignidade, terras, emprego, educação, reconhecimento. A educação era vista como fundamental para eles, pois acreditavam que a educação era o

\footnotetext{
${ }^{5}$ Segundo a Profa. Dra. Eliane Peres, em Pelotas, RS, a primeira aula para negros aconteceu na Biblioteca Pública Pelotense (BPP). De acordo com estudos desta professora: "Os cursos noturnos da BPP iniciaram suas atividades no dia 1ㅇ de fevereiro de 1877 e os últimos registros nos livros de matrículas datam de 1940. No entanto, em alguns documentos da BPP, há menção das aulas até 1956" (PERES, 2012, p. 77).
} 
caminho para resolver os problemas dos negros, que a partir dela eles seriam mais respeitados, conseguiriam arrumar emprego, ajudaria no combate ao preconceito, seriam reconhecidos. (MENDES; ALVES, 2011, p. 3-4).

Os autores ainda trazem informações sobre a organização dos negros no sentido de fundar instituições com objetivos educativos, tendo em São Paulo, por exemplo, associações dançantes, beneficentes, cívicas, recreativas, carnavalescas, literárias e esportivas.

Entretanto, somente a partir da industrialização, no início do XX, é que o ensino profissionalizante começou a ser impulsionado e popularizado, abrindo caminho para a educação dos negros no país. Porém, em nossa percepção, o acesso e permanência da etnia afro-brasileira ao modelo escolar oficial é um fato social bastante recente (anos de 1960 em diante), e as discussões sobre o ensino da cultura africana e afro-brasileira acontecem nos últimos anos do século XX' , tendo como resultado, no início do século XXI, as leis 10.639 (BRASIL, 2003) e 11.645 (BRASIL, 2008), sendo que esta última inclui o estudo das culturas indígenas. Uma das dificuldades das referidas leis é sua inclusão nos currículos escolares devido a uma gama de fatores. Para analisarmos tal questão, faz-se importante tecermos algumas considerações sobre a categoria currículo.

\section{CURRÍCULO: CONSTITUIÇÃO DE IDENTIDADES/RELAÇÕES DE PODER}

Nesta seção, nosso objetivo é tecer algumas considerações sobre algumas teorias sobre o currículo, a fim de explanar nossa opinião sobre a importância da composição de um currículo voltado para as questões inclusivas de nossa sociedade.

O termo curriculum passou a ser usado no sentido atual, segundo Tomaz Tadeu da Silva (2015), em 1918, com Bobbitt, e deveria ser uma técnica para planejar listas de conteúdos a serem ensinados, tendo em vista as futuras ocupações dos alunos, e elaborar instrumentos que permitissem à escola dizer o quanto foi apreendido por eles. Nos modelos curriculares tradicionais, a escolarização de massa tinha por objetivo "moldar corpos" para que os alunos aprendessem

\footnotetext{
${ }^{6}$ A partir de 1988, com a Constituição promulgada num contexto de abertura política, após uma ditadura militar, políticas afirmativas se esboçaram por meio da construção de uma legislação que tinha como destaque a igualdade de condições a todo cidadão brasileiro (BRASIL, 1988).
} 
como se comportar em sociedade, afinal, os futuros trabalhadores precisam ter horários e posturas condizentes com o ambiente da fábrica. Para o funcionalismo, por exemplo, cada um tem seu lugar na sociedade e, para que o corpo funcione, todos os órgãos devem trabalhar em harmonia.

Em relação às teorias críticas, estas avançaram no sentido de questionar as teorias tradicionais, "[...] as teorias críticas desconfiam do status quo" (SILVA, 2015, p. 30), alertando para o papel reprodutor da escola, trazendo para o debate termos como ideologia e resistência. "[...] o importante não é desenvolver técnicas de como fazer o currículo, mas desenvolver conceitos que nos permitam compreender o que o currículo faz" (SILVA, 2015, p. 30). A escola deve preparar futuros adultos que mandam e outros que devem ser mandados, e por isso as desigualdades sociais são enfatizadas em vez de serem superadas. A escola acaba colocando cada um no seu devido lugar. Nesse sentido, explicam-se as diferentes estruturas escolares e os diferenciados tipos de currículos de acordo com os diferentes alunos que frequentam as instituições de ensino.

Pensando em termos de educação formal no Brasil, o currículo que se apresentou a partir da iniciativa de massificação escolar tenta dar uma visão geral das áreas do conhecimento, tendo por ênfase um currículo eurocêntrico. A s muitas imagens dos livros didáticos mostram a condição de subordinação de indígenas e africanos, as pinturas de Rugendas e Debret são exemplos que mostram uma imagem negativa desses grupos étnicos. Até mesmo os grupos quilombolas parecem estar cometendo um delito, e não um ato de resistência. Isso nos remete a pensar no tipo de representação às quais os alunos são submetidos em relação à etnia africana e afro-brasileira. Por outro lado, que tipo de representação está presente na escola em relação às etnias europeias? A questão da imigração aparece marcada pela excelência do trabalho que venceu as adversidades.

Dessa forma, os livros didáticos e outros artefatos culturais ${ }^{7}$ parecem consolidar o período pós-abolição como o período de sucesso da família branca e patriarcal enquanto ideário a ser alcançado, ao mesmo tempo que continua mostrando negros em condições de trabalhos subalternos e atrelados à formação de bolsões de misérias que se constituíram nas grandes cidades, à boêmia, às bebidas e aos delitos. Assim, a cultura escolar parece estar associada ao capital cultural

\footnotetext{
${ }^{7}$ Sobre este termo, faremos inferência mais adiante no texto.
} 
das classes dominantes e, segundo Bourdieu (1989), o sucesso dos alunos ocorre porque as famílias, de forma direta ou indireta, acabam transmitindo a seus filhos o capital cultural ou ethos necessário ao sucesso escolar.

Apesar de considerarmos a questão cultural como um ponto importante de nosso estudo sobre o que diz respeito ao currículo escolar, em se tratando de pesquisas acerca do tema, não podemos deixar de apontar algumas ideias dos estudos de Michael Apple, visto que este deu início à crítica neomarxista às teorias tradicionais do currículo e ao papel ideológico desse. Segundo o intelectual, não se pode reduzir educação e currículo ao funcionamento da economia. Existe a mediação da ação humana. Nesse sentido, o campo cultural tem sua própria dinâmica, não basta saber quais conteúdos são corretos, e sim quais são considerados corretos. É preciso saber quais interesses fazem optar por esse ou aquele saber e a quem interessa que ele seja apreendido. O autor se ampara no conceito de "hegemonia cultural", o qual atinge sua máxima eficácia quando se transforma em senso comum. Entretanto, segundo ele, existe uma luta permanente para manter essa hegemonia cultural e é preciso analisar as relações de poder envolvidas no processo de seleção do currículo escolar.

Segundo Silva (2015, p. 49), "na perspectiva de Apple, o currículo não pode ser compreendido-e transformado- se não fizermos perguntas fundamentais sobre suas conexões com relações de poder". Ainda segundo Silva, Michael Apple contribuiu de forma importante para politizar e teorizar sobre currículo.

Diante do exposto nas palavras acima, ao que tudo indica, a função reprodutora da escola aparece como algo dado ao qual o currículo escolar é um grande instrumento a serviço das classes dominantes, entretanto o conhecimento é algo dinâmico, algo inerente ao ser humano, que, ciente de sua incompletude, busca respostas nos mais diversos campos. As pesquisas na área das Ciências Humanas e em especial em sociologia e sociologia da educação acabam se diversificando à medida que o acesso ao conhecimento acadêmico vai atingindo variados setores da sociedade, que continua vendo na educação uma forma de ascensão.

Dessa forma, as teorias pós-críticas acabam por desconfiar do status quo estabelecido, desconfiam das críticas feitas pelas teorias críticas. Ao que parece, a principal diferença está na análise da sociedade e das teorias do currículo pelo viés marxista, com questões de gênero, raça e etnia que se tornam temas constantes das discussões sobre o currículo. 
O pós-modernismo vem questionar o mundo moderno e o pensamento social influenciado pelo lluminismo, dessa forma, questiona a racionalidade, o homem como centro das atenções e as metanarrativas, ou seja, as grandes explicações e generalizações. Nesse sentido, questiona-se a própria instituição escolar, com fortes tradições arraigadas na modernidade. Segundo Silva (2015, p. 113), no pós-modernismo:

[...] o sujeito é fundamentalmente fragmentado e dividido. Para a perspectiva pós-modernista, nisso inspirada nos insights pós-estruturalistas, o sujeito não é o centro da ação social. Ele não pensa, fala e produz: ele é pensado, falado e produzido. Ele é dirigido a partir do exterior: pelas estruturas, pelas instituições, pelo discurso. Enfim, para o pós-modernismo, o sujeito moderno é uma ficção.

Seguindo esse raciocínio é que o pós-modernismo abre espaço para pesquisas locais, para teorias pós-críticas que rejeitam as certezas estabelecidas pelas teorias críticas. São aceitos a inovação, o hibridismo e a mestiçagem.

De forma mais restrita ao campo da linguagem, o pós-estruturalismo radicaliza a crítica ao sujeito do humanismo, dizendo que ele não passa de uma invenção cultural, social e histórica. Podemos apontar como teóricos de destaque do pós-estruturalismo Derrida e Michel Foucault, sendo que este último tem em sua contribuição que poder e saber são mutuamente dependentes. Derrida trabalha com a ideia de significante vazio, ou seja, é temporário, em movimento e constitui as identidades dos sujeitos.

Já, no que diz respeito às ideias pós-coloniais os autores dessa vertente analisam as relações de poder exercidas a partir da dominação imperialista. A análise se dá a partir de um pressuposto de globalização e da descrição das consequências da colonização europeia. Além da dominação direta, também são considerados grupos de colonos e as relações mais atuais baseadas na economia e no imperialismo cultural. Por um lado, são elencados elementos que abarcam as culturas subalternas, em que o colonizador traz a figura do outro cultural, e, por outro, os grupos colonizados enfatizam uma resistência ao imperialismo.

Nesse sentido, destacamos o pensamento de Edward Said (2006, p. 25-6):

[...] a preocupação ideológica com identidade está compreensivelmente entrelaçada com os interesses e programas de vários grupos - nem todos de 
minorias oprimidas - que desejam estabelecer prioridades que reflitam tais interesses. [...] todas as culturas são híbridas, heterogêneas, extremamente diferenciadas, sem qualquer monolitismo.

O projeto colonial na América procurou, além de subjugar o "outro" colonial por meio da força, subjugá-lo por meio da educação. Nessa perspectiva, procurou incutir os valores ocidentais de civilidade e religiosidade. Entretanto, segundo Said (2011), o hibridismo cultural faz com que as duas culturas sejam modificadas, é claro que há um amplo jogo de poder, entretanto, em suas interações, as culturas se influenciam mutuamente e já não podem ser consideradas as mesmas no processo histórico que fizeram e/ou fazem parte.

Nesse movimento denominado de teorias pós-críticas, ainda enfatizando a cultura e o modo como ela está ligada à sociologia da educação e ao currículo escolar, trazemos algumas ideias dos Estudos Culturais.

Os Estudos Culturais têm sua inauguração oficial com a fundação do Centro de Estudos Culturais Contemporâneos na Universidade de Birmingham, na Inglaterra. Os trabalhos dos intelectuais ligados ao Centro inauguram outra forma de pensar sobre Cultura. Contrapondo-se às grandes obras literárias, manifestações culturais de classes subalternas também eram levadas em conta, principalmente aquelas ligadas à classe trabalhadora inglesa. Segundo Marisa Vorraber Costa (2004, p. 18):

As obras consideradas pioneiras nos Estudos Culturais contemporâneos foram produzidas por autores provenientes de famílias de classe operária [...] Os trabalhos que inauguraram os Estudos Culturais britânicos são dos livros publicados no final da década de 1950 - The uses of literacy, de Richard Hoggart, que apareceu em 1957, e Culture and Society, de Raymond Willians, de 1958.

Ainda, segundo a autora, Raymond Willians admite que os Estudos Culturais tiveram outros predecessores já no início dos anos 1940, entretanto eles só adquiriram visibilidade a partir das publicações citadas acima. Para a autora, os Estudos Culturais vão além das fronteiras disciplinares, são saberes que migram de uma cultura para outra sem poderem ser enquadrados em nenhuma das grandes teorias da humanidade. Sua característica inicial foi constituir um projeto político de oposição com a ideia de valorizar outras culturas, marcado por um discurso de envolvimento social. Embora vários estudos possam ser considerados Estudos 
Culturais, sua característica principal está na compreensão da cultura na concepção de Raymond Willians, "[...] como forma global de vida ou como experiência vivida de um grupo social" (SILVA, 2015, p. 133).

Dessa forma, o que podemos acrescentar sobre os Estudos Culturais é que, muito embora ele tenha se destacado a partir do estudo da cultura da classe operária inglesa, essa não foi uma concepção que ficou restrita a esse campo. Agregando outros intelectuais e interesses, os Estudos Culturais preocupam-se com as questões culturais que são, em seu entendimento, permeadas de significação, identidade e poder. A partir dessas análises, os Estudos Culturais procuram caracterizar o objeto de análise como um artefato cultural. Dessa forma, todo o conhecimento pode ser importante, na medida em que essa importância é estabelecida pelas relações de poder. Tanto o currículo escolar quanto um anúncio no jornal, na televisão e, mais recentemente, nas redes sociais podem ser constituídos como artefatos culturais e passíveis de estudo.

Seguindo esse raciocínio, as questões de gênero, raça e etnia estão perpassadas por relações de poder ao longo dos tempos históricos. Em relação à sociologia da educação, esses temas têm sido alvo de discussões por teóricos contemporâneos que se debruçam em analisar a formação das identidades a partir das diferenças culturais. Celebrar a diversidade e o multiculturalismo a partir da aceitação do "outro" cultural, como se os grupos ligados à identidade branca, hétero e masculina assim o permitissem, numa atitude de benevolência, já não é mais aceito. É preciso dar espaço e voz ao "outro", num debate intercultural (APPADURAI, 2008). Para tal, é preciso que os "textos curriculares" sejam espaços de diálogo entre as culturas, e não local de privilégio de identidades dominantes. Não pode ser aceito passivamente que os livros didáticos tragam imagens semelhantes àquelas relatadas no início desse tópico. Se as editoras e sucessivos governos ainda persistem nessas ideias, parece-nos ser pelo motivo de que ainda somos influenciados pelas relações de poder de grupos que procuram por meio de todos os artefatos culturais disponíveis manter a hegemonia de uma cultura eurocêntrica, ou seja, procuram manter o status quo de séculos de dominação. 


\section{A ESCOLA COMO ESPAÇO DE NEGOCIAÇÃO, MEDIANDO FRONTEIRAS}

Mesmo diante desse quadro, apontamos as ideias de Biesta (2013), que coloca que o mundo que nos torna presença é um mundo de pluralidade e diferença. Este necessita ser um mundo que deve ser visitado, no sentido de se dar oportunidades à outridade. Precisamos valorizar a diversidade e a diferença cultural para que possamos pensar numa educação humana. O professor indiano Arjun Appadurai (2008) nos coloca que precisamos ouvir o "outro", num claro debate intercultural, ideia que parece ir ao encontro de Gert Biesta (2013, p. 153):

A responsabilidade do educador, como desejo sugerir, reside precisamente num interesse pela combinação paradoxal - ou desconstrutiva - da educação e seu desfazer [...] os educadores e os professores devem estar cientes de que aquilo que rompe a operação fluente da comunidade racional não é necessariamente um distúrbio do processo educacional, mas poderia muito bem ser o próprio ponto em que os estudantes começam a encontrar sua própria voz única, responsiva e responsável. Isso também mostra que a responsabilidade do educador, a responsabilidade educacional, é uma responsabilidade por algo que não pode ser conhecido de antemão - é uma responsabilidade sem conhecimento daquilo pelo qual se é responsável.

Seguindo essa linha de pensamento, nós perguntamos: por que muitas políticas inclusivas e afirmativas não ganham força nos espaços escolares como teoricamente determinam as leis? Quais são as forças antagônicas que se utilizam do espaço escolar? Como estão constituídos os discursos favoráveis a uma educação democrática? Se, para Biesta (2013), a educação democrática parte do princípio de que os próprios estudantes devem encontrar sua voz responsável e responsiva e de que os professores devem ser responsáveis por aquilo que desconhecem de antemão, então perguntamos: por que tanta rigidez nos currículos? Por que preconizar que os currículos devem ser iguais para que todos tenham as mesmas oportunidades de aprendizado, se somos singulares e sujeitos objetivados por realidades diferentes, portanto, sujeitos únicos?

Por que as mantenedoras não investem em capacitação profissional reflexiva? Por que ordens e leis muitas vezes já nascem com letra morta? Seria para satisfazer de imediato as reivindicações de grupos "minoritários" que conseguem ter alguma voz em determinado momento? Para parecer politicamente correto? São questões que parecem ecoar sem respostas. 
Nesse sentido, Ball (2002) contribui para elucidar algumas das questões colocadas acima: a partir da ideia de enactment, num sentido de atuação, as políticas são interpretadas e materializadas de diferentes formas. Dessa maneira, segundo o autor, os professores não são meros implementadores de políticas, existe sempre o contexto que deve ser analisado. Seguindo as palavras de Mainardes e Stremel (2015, citando BALL; MAGUIRE; BRAUN, 2012), as dimensões contextuais são: contextos situados, culturas profissionais, contextos materiais e contextos externos. A partir da análise desses quatro fatores é que podemos responder questões como as que foram colocadas no parágrafo acima. Mainardes e Stremel (2015) citam o que Ball chamou de não implementação criativa ou implementação performativa, em que as escolas dão alguma atenção à política e a colocam nos documentos escolares, entretanto, na prática, a mudança não é sempre efetivada.

Podemos apontar outros questionamentos: por que então não trabalhar de forma inclusiva? Quais são as barreiras que impõem a exclusão em uma instituição que deveria promover o debate sobre a igualdade social?

A partir do que tem sido dito até aqui, um olhar mais detalhado aos estudos sobre performatividade e políticas gerencialistas nos parece ser necessário. Segundo Stephen Ball (2005), a performatividade influencia as identidades docentes. Mas, então, o que viria a ser a performatividade?

A performatividade é uma tecnologia, uma cultura e um método de regulamentação que emprega julgamentos, comparações e demonstrações como meios de controle, atrito e mudança. Os desempenhos de sujeitos individuais ou de organizações servem de parâmetros de produtividade ou de resultado, ou servem ainda como demonstrações de "qualidade" ou "momentos" de promoção ou inspeção. Eles significam ou representam merecimento, qualidade ou valor de um indivíduo ou organização dentro de uma área de julgamento, tornando os "silêncios audíveis" (Bauman, 1991, p. 5). A questão de quem controla a área a ser julgada é crucial e um dos aspectos importantes do movimento da reforma educacional global são as disputas localizadas para se obter o controle e introduzir mudanças na área a ser julgada e em seus valores. Performatividade é o que Lyotard (1984, p. 24) chama de "os terrores (soft e hard) de desempenho e eficiência" - o que significa: "seja operacional (ou seja, comensurável) ou desapareça". Isso decorre em boa parte da "inclinação natural da prática moderna - intolerância" (Bauman, 1991, p. 8). Para Lyotard, performatividade compreende os aspectos funcional e instrumental da modernidade, bem como a exteriorização do conhecimento e sua transformação em mercadoria. (BALL, 2005, p. 543-4). 
Dessa maneira, a performatividade traz uma ideia de eficiência das escolas. Nesse sentido, os profissionais da educação devem trabalhar para melhorar os índices de desempenho e para isso os gestores têm o papel fundamental de pôr em prática as políticas gerencialistas na escola. Entretanto essas políticas não têm por objetivo democratizar o conhecimento em busca de uma sociedade mais igualitária, de forma a dirimir as injustiças sociais que têm seus fundamentos em uma sociedade machista, patriarcal, classista e eurocêntrica. Pelo contrário, as políticas gerencialistas, ao que tudo indica, reforçam as diferenças sociais a partir de uma roupagem de eficácia e modernidade.

Mas o que na verdade acontece é a perda da autonomia docente, pois os professores, para provarem sua eficiência, precisam ensinar ao aluno como marcar os testes padronizados com o objetivo de manter sua escola nos índices aceitáveis. Segundo Diane Ravitch (2011), as reformas implementadas no sistema educacional americano nos últimos anos, tendo como enfoque os resultados nos testes padronizados de linguagem e matemática, têm revelado sérios problemas. Sua análise demonstra que os alunos são literalmente treinados para as provas e, ao final do processo, os discentes não conseguem responder questões simples que exijam reflexão crítica sobre a realidade em que estão inseridos.

Nesse sentido, no Brasil, podemos visualizar práticas governamentais que visam ao controle gerencialista da escola, tais como os testes padronizados e o discurso de que o fracasso escolar está atrelado ao trabalho docente, numa crescente política de responsabilização do professor. Garcia, Hypolito e Vieira (2005) apontam que:

[...] professoras são a todo o momento seduzidas e interpeladas por discursos que dizem como elas devem ser e agir para que sejam mais verdadeiras e perfeitas em seu ofício. Diferentes "regimes do eu" e formas de subjetivação concorrem para essas definições e lutam pela imposição de significados acerca de quem as professoras devem ser em determinadas conjunturas, como devem agir e qual o projeto formativo que docentes e escolas devem levar adiante perante os desafios da cultura e do mundo contemporâneo. (GARCIA; HYPOLITO; VIEIRA, 2005, p. 47).

Entretanto, há de se buscar formas de construir problematizações, a fim de superar determinadas situações como as explicitadas acima, e para isso podemos nos apoiar em autores como Gert Biesta (2013) e Arjun Appadurai (2008), assim 
como Paulo Freire (1987), no sentido de problematizar para uma educação mais humana e pela autonomia do trabalho docente.

Arriscamos dizer que a busca pela educação democrática deve ser incessante e como se discute nos cursos de formação: "Não há receita de bolo pronta." A questão da educação democrática passa pelo refletir sobre a prática de forma que se busque uma educação que possibilite que a voz do outro seja ouvida, num debate intercultural, num "visitar o outro". No caso da educação mais humana, deve-se levar em conta elementos importantes da interculturalidade, em que visitar significa que estamos no lugar do outro, entretanto a partir de nossa subjetividade, ou seja, não perdemos nossa autenticidade, nossa visão de mundo, mas procuramos compreender o "outro" sem pré-julgamentos ou pré-conceitos. Assim, poderemos estabelecer um debate que leve em conta as considerações e as contribuições do "outro".

São muitas as indagações, questionamentos, poderíamos apontar várias ideias, mas a que ocorre com mais força neste momento é o conceito "visitar" de Arendt, trabalhado por Biesta (2013, p. 124): “Visitar 'não' é, portanto, ver pelos olhos de outra pessoa, mas ver 'com nossos próprios olhos' a partir de uma posição que não é a nossa - ou, para ser mais preciso, numa história muito diferente da nossa"; é pensar que a educação humana e que os educadores humanos devem deixar uma clara mensagem aos educandos: Não faça aos outros o que não gostarias que fizessem a ti. E, é claro, continuar lutando contra políticas que desumanizam a educação, desumanizam a comunidade escolar, desumanizam os educadores e, por fim, desumanizam os educandos, àqueles que serão os atores sociais que terão a responsabilidade de tomar decisões em nosso futuro próximo. Paulo Freire (1987) escreveu sobre uma educação em que o educando e o educador são sujeitos do mesmo processo.

Dessa forma, um currículo pensado nas condições contextualizadas de aprendizagem e necessidade dos educandos é uma iniciativa que pode contribuir para a formação de uma sociedade mais humana. Um currículo em que o que é apreendido pelos atores sociais possa contribuir para a construção de sujeitos ativos que colaborem para a democracia social.

Dessa forma, um profissional crítico precisa ter a capacidade de pensar sobre sua prática, de pesquisar, de buscar meios para tratar com um currículo construído em meio às relações de poder. Um currículo de respeito às diferen- 
ças, em que se percebam as diferenças sem o estranhamento do "outro", que esse outro possa se ver contemplado no currículo praticado. Ou nas palavras de Arjun Appadurai (2008), para quem "[...] a característica mais valiosa da cultura é o conceito de diferença".

Nesse sentido, Silva (2000), ao trabalhar conceitos como identidade e diferença, aponta para a necessidade de uma problematização deles no sentido de questionar quais as implicações políticas que estão em jogo. Seu objetivo principal é discutir a importância de se conviver com as diferenças e ter um projeto pautado para tal; para ele, não se pode mais somente aceitar, são necessários questionamentos.

Dessa maneira, acreditamos que a fonte do sucesso ou do fracasso de determinada política, lei ou diretriz curricular possa estar no grau de politização e de resistência imprimida pelos docentes. Uma sólida formação docente embasada em princípios emancipatórios pode contribuir para a construção de uma sólida identidade docente, instrumentalizando esses para resistir ${ }^{8}$ aos processos gerencialistas e performativos que bombardeiam o contexto social atual.

Assim, práticas pedagógicas emancipatórias, que pensem na construção de currículos em conjunto com os alunos, suas necessidades, expectativas e possibilidades, de acordo com as ideias apregoadas por Ladson-Billings (2008), de pedagogias culturalmente relevantes, poderiam trazer um novo sentido sobre a educação aos atores sociais envolvidos.

\section{PALAVRAS FINAIS}

Durante este trabalho, procuramos tecer algumas considerações sobre diferentes discursos em relação ao currículo. Embora tenhamos escolhido somente alguns teóricos para exemplificar nossas ideias, não apontamos nenhum como correto ou errado. Acreditamos que cada teoria foi própria das discussões do seu tempo.

Nossa tendência é trabalhar com as teorias pós-críticas, com uma visão de currículo que favoreça o interculturalismo e a defesa dos grupos "minoritários", grupos que resistem à opressão colonialista, em que se priorize um currículo

\footnotetext{
${ }^{8}$ Falamos em resistência no sentido de microrresistências, imprimido por Michel de Certeau (1994).
} 
para a diferença e a identidade de pessoas incluídas na sociedade. Para tal, faz-se necessário um intenso debate crítico, o que exige colocar-se no lugar do "outro", exige uma forma de convivência entre o "outro e o "eu", ou do "outro" e "nós", num claro debate intercultural. Nossa sociedade necessita de currículos escolares que trabalhem o conhecimento científico de forma significativa, e a valorização da cultura local nos parece ser um caminho para essa demanda.

\section{REFERÊNCIAS}

ALMEIDA, Alfredo Wagner Berno. Os quilombos e as novas etnias: é necessário que nos libertamos da definição arqueológica. In: LEITÃO, Sérgio (Org.). Direitos territoriais das comunidades negras rurais. São Paulo: Instituto Socioambiental, 1999. (Documentos do ISA, n. 5).

APPADURAI, Arjun. Só nos resta dialogar com o 'outro'. Entrevistador: Vitor Belanciano, [S.I.], 28 de outubro de 2008. Disponível em: www.globalizaçao/cosmopolitismo/internet. Acesso em: 30 maio 2013.

ÁVILA, Cristiane Bartz. Entre esquecimentos e silêncios: Manuel Padeiro e a memória da escravidão no distrito de Quilombo, Pelotas, RS. 2014. 185f. Dissertação (Mestrado em Memória Social e Patrimônio Cultural) - Instituto de Ciências Humanas, Universidade Federal de Pelotas, Pelotas, RS, 2014.

ÁVILA, Cristiane Bartz de; RIBEIRO, Maria de Fátima Bento. Cultura, multiculturalismo e interculturalidade: as "tias minas" da cidade de Pelotas-RS e seu legado cultural. In: CONINTER - CONGRESSO INTERNACIONAL INTERDISCIPLINAR EM CIÊNCIAS E HUMANIDADES, 2., 2013, Belo Horizonte. Anais [...]. Belo Horizonte: UFMG, 2013. p. 1-16.

BALL, Stephen J. Profissionalismo, gerencialismo e performatividade. Cadernos de Pesquisa, São Paulo, v. 35, n. 126, p. 539-64, set./dez. 2005.

BALL, Stephen J. Reformar escolas/reformar professores e os terrores da performatividade. Revista Portuguesa de Educação, Braga, Portugal, v. 15, n. 2, p. 3-23, 2002.

BIESTA, Gert. Para além da aprendizagem. Educação democrática para um futuro humano. Belo Horizonte: Autêntica, 2013.

BOURDIEU, Pierre. A escola conservadora. As desigualdades frente à escola e à cultura. Educação em Revista, Belo Horizonte, n. 10, p. 3-15, dez. 1989. 
BRASIL. Lei 11.645, de 10 de março de 2008. Altera a Lei n. 9.394, de 20 de dezembro de 1996, modificada pela Lei n. 10.639, de 9 de janeiro de 2003, que estabelece as diretrizes e bases da educação nacional, para incluir no currículo oficial da rede de ensino a obrigatoriedade da temática "História e Cultura Afro-Brasileira e Indígena". Disponível em: http://www.planalto.gov.br/ccivil_03/_ato2007-2010/2008/lei//11645.htm. Acesso em: 10 maio 2014.

BRASIL. Lei 10.639, de 9 de janeiro de 2003. Altera a Lei n. 9.394, de 20 de dezembro de 1996, que estabelece as diretrizes e bases da educação nacional, para incluir no currículo oficial da Rede de Ensino a obrigatoriedade da temática "História e Cultura Afro-Brasileira", e dá outras providências. Disponível em: http://www.planalto.gov.br/ccivil_03/leis/2003/ |10.639.htm. Acesso em: 10 maio 2014.

BRASIL. Constituição Federal. 1988. Disponível em: http://www.planalto.gov.br/ccivil_03/ constituicao/constituicao.htm. Acesso em: 1ㅇjan. 2014.

CANDAU, Joel. Conflits de mémoire: pertinence d'une métaphore? In: BONNET, Véronique (sous la direction de). Conflits de mémoire. Paris: Khartala, 2004.

CERTEAU, Michel de. A invenção do cotidiano: artes de fazer. Petrópolis, RJ: Vozes, 1994. COSTA, Marisa Vorraber (Org.). Estudos culturais em educação: mídia, arquitetura, brinquedo, biologia, literatura, cinema... 2. ed. Porto Alegre, RS: Editora da UFRGS, 2004.

CRUZ, Mariléia dos Santos. Uma abordagem sobre a história da educação dos negros. In: ROMÃO, Jeruse. História da educação dos negros e outras histórias (Org.). Brasília: Ministério da Educação, Secretaria de Educação Continuada, Alfabetização e Diversidade, 2005. p. 21-33.

CUNHA, Olivia Maria Gomes da; GOMES, Flávio dos Santos (Org.). Quase cidadão: histórias e antropologia da pós-emancipação no Brasil. Rio de Janeiro: Editora FGV, 2007.

FERNANDES, Florestan. A integração do negro na sociedade de classes: o legado da raça branca. 5. ed. São Paulo: Globo, 2008.

FREIRE, Paulo. A pedagogia do oprimido. 17. ed. Rio de Janeiro: Paz e Terra, 1987.

GARCIA, Maria Manuela Alves; HYPOLITO, Álvaro Moreira; VIEIRA, Jarbas Santos. As identidades docentes como fabricação da docência. Educação e Pesquisa, São Paulo, v. 31, n. 1, p. 45-56, jan./abr. 2005. 
LADSON-BILLINGS, Gloria. Os guardiões de sonhos. O ensino bem-sucedido de crianças afro-americanas. Belo Horizonte: Autêntica, 2008.

MAINARDES, Jefferson; STREMEL, Silvana. Informações sobre a abordagem do ciclo de políticas. Ponta Grossa, PR: UEPG, 2015. Disponível em: www.uepg.br/gppepe. Acesso em: 5 ago. 2017.

MENDES, Ana Laura R.; ALVES, Bruna Pereira. Os negros e a educação: uma luta constante. Revista Pandora Brasil - "Cultura e materialidade escolar", [S.I.], Edição especial n. 4, p. 1-16, mar. 2011.

PERES, Eliane. Sob(re) o silêncio das fontes... A trajetória de uma pesquisa em história da educação e o tratamento das questões étnico-raciais. Revista Brasileira de História da Educação, Maringá, PR, n. 4, p. 75-102, jul./dez. 2002.

RAVITCH, Diane. Vida e morte do grande sistema escolar americano: como os testes padronizados e o modelo de mercado ameaçam a educação. Porto Alegre: Sulina, 2011.

SAID, Edward W. Cultura e imperialismo. São Paulo: Companhia das Letras, 2011. 459p.

SILVA, Tomaz Tadeu da. Documentos de identidade: uma introdução às teorias do currículo. 2. ed. Belo Horizonte: Autêntica, 2015.

SILVA, Tomaz Tadeu da (Org.). Identidade e diferença: a perspectiva dos estudos culturais. 4. ed. Petrópolis, RJ: Vozes, 2000.

SKIDMORE, Thomas E. Preto no branco: raça e nacionalidade no pensamento brasileiro. Rio de Janeiro: Paz e Terra, 1976.

\section{Sobre os autores:}

Cristiane Bartz de Ávila: Doutoranda em Educação, com bolsa CAPES, mestre pelo Programa de Pós-Graduação em Memória Social e Patrimônio Cultural, especialista em História da Educação pela Faculdade de Educação e graduada em Licenciatura Plena em História, todos pela Universidade Federal de Pelotas (UFPel). E-mail: crisbartz40@yahoo.com.br, Orcid: http://orcid.org/0000-0002-2932-6480

Álvaro Moreira Hypolito: Doutor em Curriculum and Instruction (University of Wisconsin - Madison). Mestrado em Educação pela Universidade Federal de Minas Gerais (UFMG). Especialista em Educação e Sociedade, graduado em Licenciatura 
Curta em Educação Artística e graduação em Licenciatura Plena em Pedagogia, todos pela Universidade Federal de Pelotas (UFPel). E-mail: hypolito@ufpel.edu. br, Orcid: http://orcid.org/0000-0003-1487-0413

Recebido em 15 de outubro de 2019. Aprovado em 20 de maio de 2020. 